Brit.J. prev. soc. Med. (1962), 16, 30

\title{
REPRESENTATIONS OF NATIONAL, REGIONAL, AND LOCAL STATISTICS
}

\author{
BY
}

\author{
I. N. SUTHERLAND
}

Department of Health for Scotland

One of the frequently attempted and often unsuccessful efforts to show the distribution of some variable, e.g. morbidity or mortality, is the production of a map in which areas are shaded according to the intensity of attack or some other measure of distribution. Among many difficulties in this presentation is the impossibility of giving suitable weight to individual local authority units and especially of showing the often preponderant populations of cities, towns, and conurbations. If, for instance, a map of Scotland is shaded according to the distribution of some variable, the County of Sutherland (area $1,297,849$ acres, population 13,442) swamps the City of Glasgow (area 39,725 acres, population 1,054,913). This is no more than can be expected to arise from the lack of significant correlation between sizes and populations of local health authorities, to which more precise reference will be made below.

Attempts to secure methods of representation which will smooth out some, even all, of these inequalities are of interest in demography, epidemiology, and medical geography. In the description which follows two different attempts will be discussed. The methods have been applied to Scotland, but they should have wider validity.

As a preliminary it may be stated that Scotland covers 29,785 square miles and has a population (1961 Census) of $5,178,490$. Within the country are 33 counties; but as the Counties of Perth and Kinross form a single local health authority there are 32 county local health authorities. Within these there are twenty "large burghs" which are essentially autonomous in public health matters; they are also local health authorities (L.H.As). Lastly, there are four cities which are L.H.As and are treated both as autonomous counties and as large burghs.

For purposes of hospital administration and for many other demographic purposes, e.g. in the reports of the Registrar General (Scotland), the country is $\vec{\oplus}$ divided into five (hospital) regions. Each region i ? general has a central city, except the northern regio in which the large burgh of Inverness is the focat town, fulfilling functions similar to those of the cities in other regions. Three of the other four regions include, in addition to the city, one or more large burgh; exceptionally, the North-eastern region has no large burgh outside the city of Aberdeen. A tabulation of these data, with some populations, is shown in Table I.

TABLE I

HOSPITAL REGIONS, SHOWING DISTRIBUTION OF
POPULATION, BY LOCAL HEALTH AUTHORITIES, 1961

\begin{tabular}{c|c|c|c|c}
\hline \multirow{2}{*}{ Regions } & \multicolumn{3}{|c|}{ Local Health Authorities, with Populations } \\
(in brackets)
\end{tabular}


A map of Scotland (shaded as explained later) is available in Fig. 4 (p. 37); in order to make clearer the areas and dispositions of the hospital regions an exploded map is shown in Fig. 1. The focal town is the only one shown in each hospital region. The counties and large burghs making up the region are

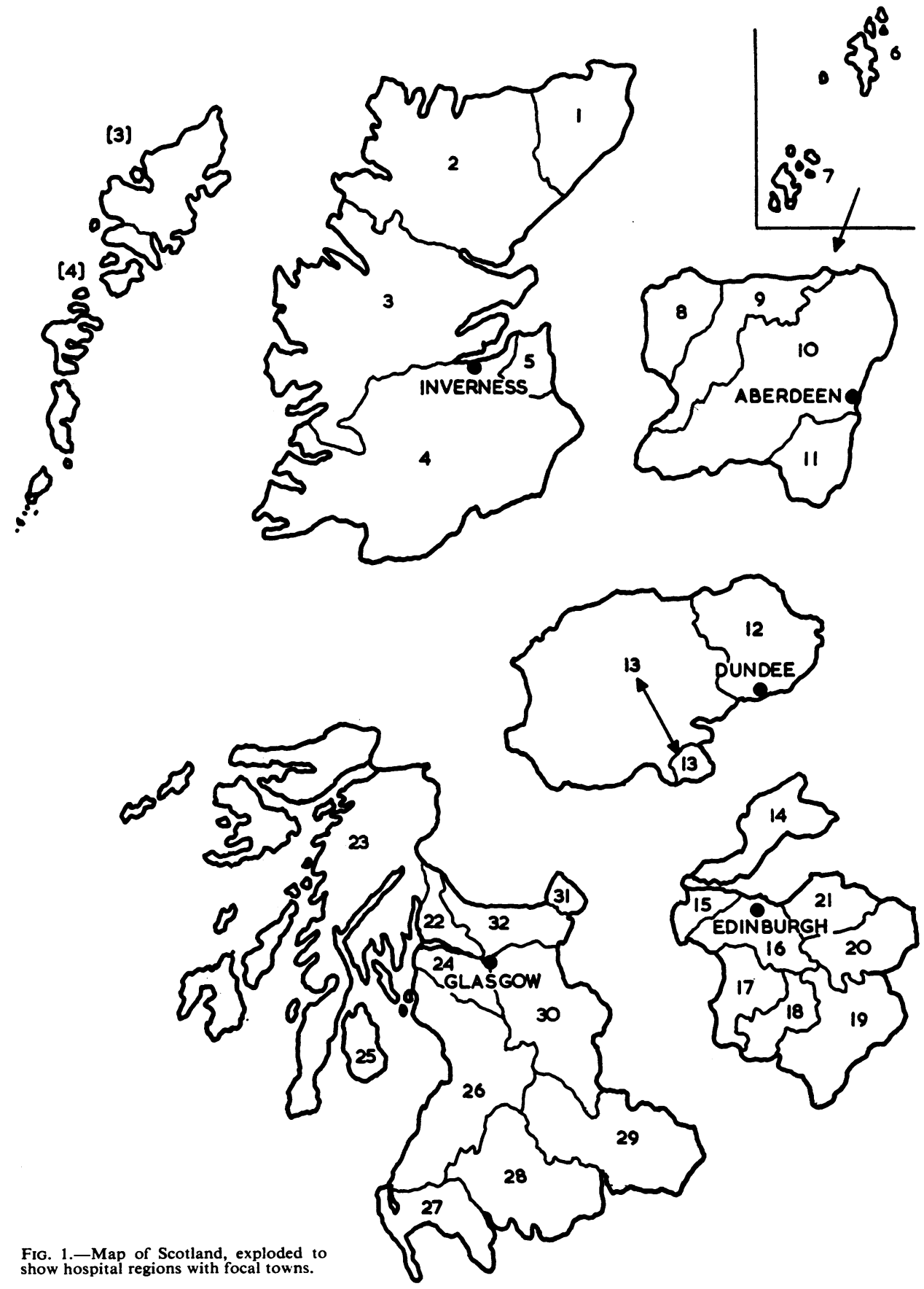

FIG. 1.-Map of Scotland, exploded to 
numbered or lettered, respectively, according to a plan in which, in general, progression is from the north of the focal town, anticlockwise (see also Table II).

TABLE II

HOSPITAL REGIONS, SHOWING CODING OF COUNTIES AND LARGE BURGHS, CORRESPONDING WITH FIG. 1.

\begin{tabular}{|c|c|c|c|c|}
\hline Regions & \multicolumn{2}{|c|}{ Counties (numbers) } & \multicolumn{2}{|l|}{$\begin{array}{l}\text { Large Burghs included in } \\
\text { Counties (letters) }\end{array}$} \\
\hline $\begin{array}{l}\text { Nor- } \\
\text { thern }\end{array}$ & $\begin{array}{l}\text { Caithness } \\
\text { Sutherland } \\
\text { Ross and Cromarty } \\
\text { Inverness } \\
\text { Nairn }\end{array}$ & $\begin{array}{l}1 \\
2 \\
3 \\
4 \\
5\end{array}$ & $\begin{array}{l}\overline{-} \\
\begin{array}{c}\text { [Inverness Burgh-shown } \\
\text { as a focal town] }\end{array}\end{array}$ & \\
\hline $\begin{array}{l}\text { North- } \\
\text { Eastern }\end{array}$ & $\begin{array}{l}\text { Zetland } \\
\text { Orkney } \\
\text { Moray } \\
\text { Banff } \\
\text { Aberdeen } \\
\text { Kincardine }\end{array}$ & $\begin{array}{r}6 \\
7 \\
8 \\
9 \\
10 \\
11\end{array}$ & $\begin{array}{c}\overline{-} \\
\overline{-} \\
\begin{array}{c}\text { [Aberdeen City-shown } \\
\text { as a focal town] }\end{array}\end{array}$ & \\
\hline Eastern & $\begin{array}{l}\text { Angus } \\
\text { Perth and Kinross }\end{array}$ & $\begin{array}{l}12 \\
13 \\
\end{array}$ & $\begin{array}{l}\text { [Dundee-shown as a } \\
\text { focal town] } \\
\text { Arbroath } \\
\text { Perth Burgh }\end{array}$ & $\begin{array}{l}\mathbf{a} \\
\mathbf{b}\end{array}$ \\
\hline $\begin{array}{l}\text { South- } \\
\text { Eastern }\end{array}$ & $\begin{array}{l}\text { Fife } \\
\text { West Lothian } \\
\text { Midlothian } \\
\text { Peebles } \\
\text { Selkirk } \\
\text { Roxburgh } \\
\text { Berwick } \\
\text { East Lothian }\end{array}$ & $\begin{array}{l}14 \\
15 \\
16 \\
17 \\
18 \\
19 \\
20 \\
21\end{array}$ & $\begin{array}{l}\text { Dunfermline } \\
\text { Kirkcaldy } \\
\begin{array}{c}\text { [Edinburgh - shown as a } \\
\text { focal town] } \\
= \\
=\end{array}\end{array}$ & $\begin{array}{l}\text { c } \\
\text { d }\end{array}$ \\
\hline Western & $\begin{array}{l}\text { Dunbarton } \\
\text { Argyll } \\
\text { Renfrew } \\
\text { Bute } \\
\text { Ayr } \\
\text { Wigtown } \\
\text { Kirkcudbright } \\
\text { Dumfries } \\
\text { Lanarkshire } \\
\\
\\
\text { Clackmannan } \\
\text { Stirling }\end{array}$ & $\begin{array}{l}22 \\
23 \\
24 \\
\\
25 \\
26 \\
27 \\
28 \\
29 \\
30\end{array}$ & $\begin{array}{l}\text { Dumbarton } \\
\text { Clydebank } \\
\text { Port-Glasgow } \\
\text { Greenock } \\
\text { Paisley } \\
\text { Ayr Burgh - } \\
\text { Kilmarnock } \\
\text { Dumfries Burgh } \\
\text { [Glasgow-shown as a } \\
\text { focal town] } \\
\text { Rutherglen } \\
\text { Hamilton } \\
\text { Motherwell and Wishaw } \\
\text { Airdrie } \\
\text { Coatbridge } \\
\text { Falkirk - } \\
\text { Stirling Burgh }\end{array}$ & $\begin{array}{l}\mathbf{e} \\
\mathbf{f} \\
\mathbf{g} \\
\mathrm{h} \\
\mathbf{i} \\
\mathbf{j} \\
\mathbf{k} \\
\mathbf{1}\end{array}$ \\
\hline
\end{tabular}

The average county L.H.A. has a population of 75,466 (range 7,091 to 344,044 : S.D. 7,642). The average large burgh (including cities) L.H.A. has a population of 115,149 (range 19,533 to $1,054,913$ : S.D. 22,138).

The average county L.H.A. area is 930.8 sq. $\mathrm{mls}$ (range 55 to $4,088 \mathrm{sq}$. $\mathrm{mls}$ ), the average large burgh L.H.A. area is 11.35 sq. mls (range 1.85 to 62.1 sq. mls: S.D. 15·1).

There is no significant correlation between areas and 1961 Census populations. The following coefficients were derived:

(a) For 32 county L.H.A.s $r=+0.0935$

(b) For 24 large burgh L.H.A.s (including cities)

(c) For 56 L.H.A.s in Scotland $r=+0.0878$$$
r=-0.0684
$$

The last coefficient has tended to negativity because of the inclusion of several cities which are small in area but large in total population. This difference does not show in $(a)$ or $(b)$ above; in general, there is a slight association between geographical and population sizes of towns and even of counties, within each group.

\section{METHODS}

Various arrangements and representations of these areas and of their populations can be made. The first attempt was an arrangement whereby each L.H.A. was given a square or polygon of equal area. In this way a formal representation of each region and of Scotland as a whole could be made. On later consideration it was thought that a better representation could be made-with some improvement in the relative relations of geography and population-by using a series of circles. Various attempts were made to devise a suitable arrangement which would give some approximation to the facts of geography and demography.

In the end a series of concentric circles was adopted as best meeting the needs of this type of presentation. In the figures which have been devised, therefore, the first description is that they are concentric. In the ideal region, and for this purpose the Western, Southeastern, and Eastern provide sufficient diverse units to meet these needs, there is a central circle and two concentric annuli. The central circle represents the city which is the focal point of the region. It is surrounded by an annulus which represents the large burghs within the region. The second and outer annulus represents the counties in the region.

Two regions lack the complete set of L.H.As. In the Northern there is no city and therefore the inner annulus becomes a circle; in the North-eastern, there is no separate large burgh, so the inner annulus is missing. These deficiencies in the pattern are not regarded as major defects.

This arrangement has a considerable attraction in representing what is often the true state of population distribution, communications, and even such health matters as the spread of communicable disease. It may give a distorted picture if these criteria are not met. 
The next question was how to measure these representations of the regions and how to meet the descriptive needs of certain data. The first attempt was to give to each local health authority unit an equal space in the schematic diagram. Various methods of splitting the annuli could have been adopted, but in the end the sectoral method was used. So far, therefore, the representation can be described as concentric sectoral.

If, in addition (as has been foreshadowed), each L.H.A. unit is given an equal area within a circle, an annulus, or a sector, the distribution becomes iso-archic (the hyphen has been introduced only to show its derivation and will not be again printed). Such distribution is shown in Fig. 2 (overleaf) which, to sum up, is a concentric sectoral isoarchic representation of Scotland. It should perhaps again be mentioned that the northern region and the northeastern region each lack one component. In Fig. 2, each county or large burgh L.H.A. has been numbered or lettered to show its correspondence with Fig. 1 and Table II.

This type of representation has obvious advantages in comparing rates of morbidity, mortality, or other variables which differ between L.H.As. It has, on the other hand, the disadvantage that it gives no weight to the very different population sizes of the L.H.A. areas.

The next stage, therefore, was the drawing of a somewhat similar representation in which the area occupied by each circle, annulus, or sector would be proportional to the population within that area. Since this last representation equalizes populations it is not isoarchic, but isodemic. A concentric sectoral isodemic representation of Scotland is shown as Fig. 3 (overleaf).

It was feared that perhaps the isodemic method might lead to considerable dislocation of large burghs relative to the geographical counties in which they lie. Fortunately, however, the tendency is for populous large burghs to lie in populous counties and therefore the sectors describing large burgh populations do correspond fairly closely in their location to their appropriate counties.

The isodemic representation has the advantage that areas are weighted for their populations and therefore distribution maps of variables depict areas which correspond to the local populations. This is in many ways an advantage when compared with the crude method of shading maps showing the actual geographical size of such areas.
Both isoarchic and isodemic representations involve some spatial distortion though it is not difficult to translate Fig. 1 into Figs 2 and 3. In the two latter, some degree of separation of regions has been maintained, largely because the resultant picture is slightly easier to study than when the circles touch. In fact the Eastern region touches all the others and it has therefore been given a central placing in Figs 2 and 3. The centres of the circles have been kept in rough correspondence with the centres area of of the geographical regions.

The only exception to strict rotational order of numbers and letters was the transposition of Counties 6 (Zetland) and 7 (Orkney) to conform more closely to actual topography.

\section{Discussion}

Any re-arrangement such as those described has to be subject to some conventions, often quite useful ones. Thus the North-eastern region includes two island counties which are closer to part of the Northern region than to that to which they were allocated; but the allocation started a long time ago, is in regular use elsewhere, and has considerable arguments (e.g. commercial and administrative) in its favour.

The isoarchic representation can well be regarded as an intermediate stage between the crudity of the use of ordinary maps and the relative refinement of isodemic representation. Further, it gives an answer to a different question, such as comparisons between the experiences of different L.H.As, regardless of their size, and of the contributions which they make, as L.H.As, to some national picture.

Schematic representations such as those described can give a good view not only of a national picture but of considerable detail. Thus, each annulus has only to be scanned to give the proportion of L.H.As in the county or large burgh aggregate (and, in isodemic representations, in the population of each aggregate) possessing or lacking the recorded properties. Further refinement, without loss of accuracy, is to be obtained by differential shading.

It is also to be hoped that these representations maintain some relation to the shape of Scotland as it is known. To the writer they seem to be readily transferable and to have advantages. Corresponding exercises may be of value in countries with demographic data of equal accuracy. 


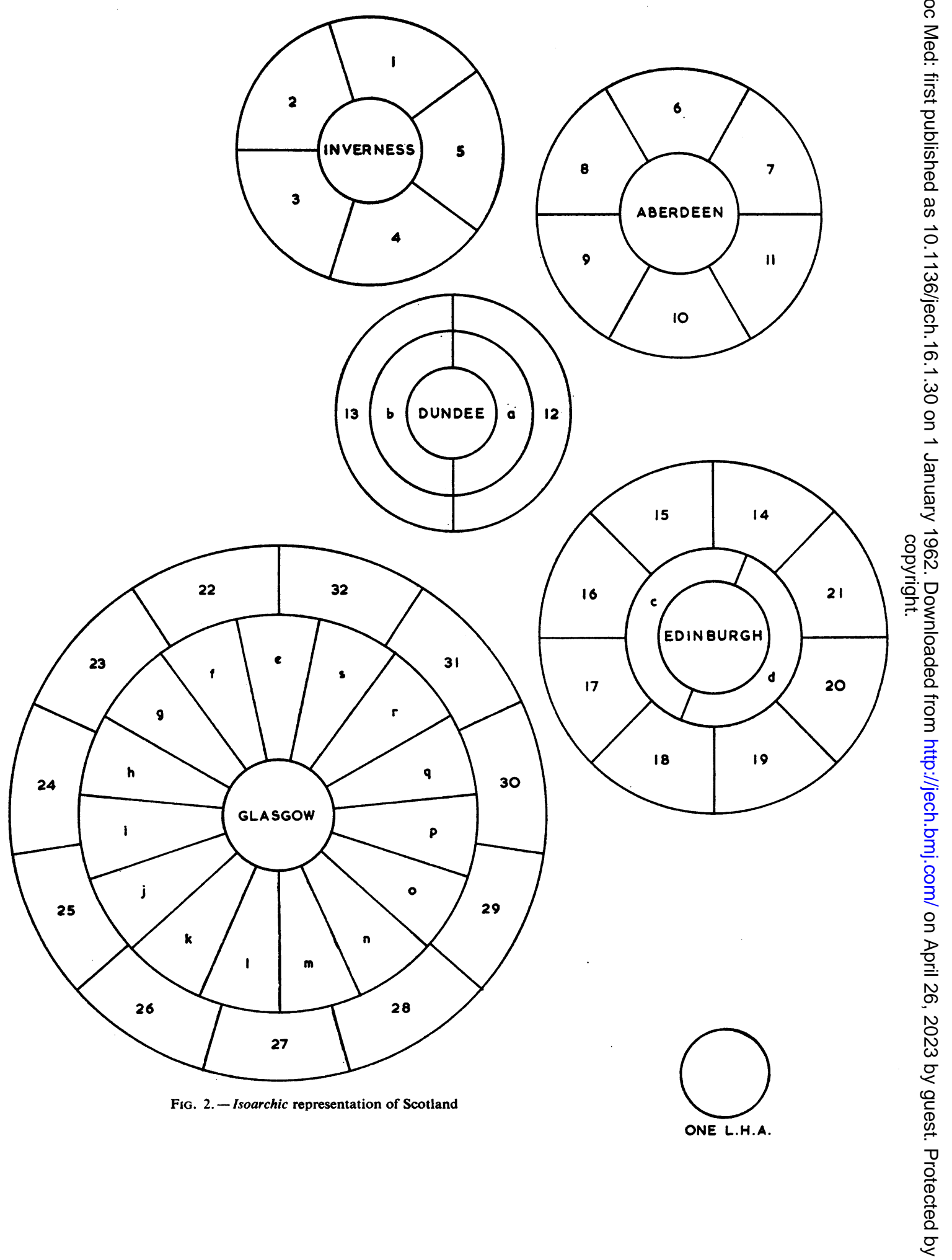




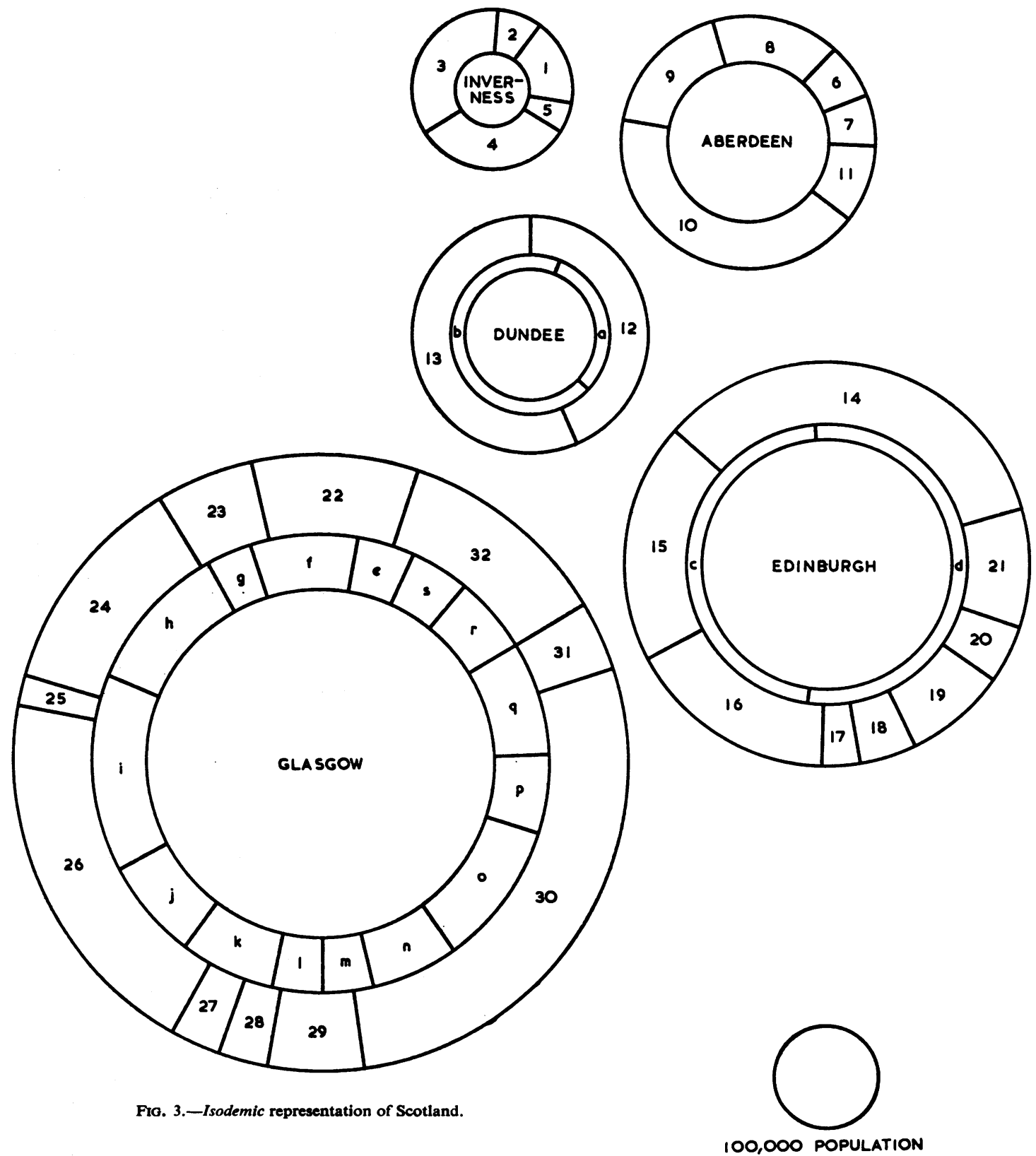




\section{One Application}

The statistic selected for application was L.H.A. death rate from respiratory tuberculosis in 1959 (published in Table 4 of the Annual Report of the Registrar-General (Scotland)). It may be mentioned (in expansion of the published Table) that, of the eight L.H.As sharing the apparent median value of $0 \cdot 7$ per 1,000 , four (Ayr Burgh, Kirkcudbright, Perth and Kinross, and Dundee) had rates below the median of 0.694 per 1,000 . The data can be conveniently summarized as in Table III.

Table III makes it clear that high rates were a problem of the Western region, with lesser problems in the North and East; and that large burghs, especially in the West (including the city of Glasgow), carried a preponderant share of the burden with the western counties a fair second.

The translation of these data into a map (Fig. 4, opposite) gives no clear idea of where the problems lie and of their relative magnitude (as measured by the simple dichotomy of the median rate).

The representations (overleaf) of Fig. 5-isoarchic - and Fig. 6 - isodemic - not only clarify but give quantitative help in pin-pointing the regional, local, and population groups involved or spared.

Obviously differential shading could give more detail at the cost of greater elaboration; for the present purpose only the simplest example has been used. A number of copies of blank representations has been made (Figs 2 and 3), and it is hoped to use these elsewhere to record, in these ways, other data of special interest in medical geography.

\section{SUMMARY}

In order to avoid the distortion of statistics which is often produced by mapping them, two representations have been devised according to the following principles:

(a) Sub-division into (hospital) regions;

(b) Sub-division of each region into a "focal town", a ring of burghal L.H.As, and an outer ring of county L.H.As;

(c) The representation of these groups of authorities as concentric circles and rings;

(d) The division into sectors corresponding to L.H.A. areas;

(e) The decision either to give each L.H.A. area an equal area in the plan-resulting in the concentric sectoral isoarchic representation-, or to make the circle, annulus, or sector area proportional to the population size of the L.H.A.-resulting in the concentric sectoral isodemic representation.

TABLE III

LOCAL HEALTH AUTHORITY GROUPS IN SCOTLAND WITH DEATH RATES FROM RESPIRATORY TUBERCULOSIS UNDER OR OVER MEDIAN IN 1959

(Mortality Data from Annual Report for 1959 of the Registrar General (Scotland).)

\begin{tabular}{|c|c|c|c|c|c|c|c|c|c|c|}
\hline & & & \multicolumn{8}{|c|}{ Local Health Authorities, with Group Total Populations (in brackets) } \\
\hline \multicolumn{3}{|c|}{ Regions } & \multicolumn{2}{|c|}{ Cities } & \multicolumn{2}{|c|}{ Large Burghs } & \multicolumn{2}{|c|}{ Counties } & \multicolumn{2}{|c|}{ All L.H.As } \\
\hline & & & Under & Over & Under & Over & Under & Over & Under & Over \\
\hline Northern .. & . & .. & - & - & - & $\stackrel{1}{(29,733)}$ & $(119,680)$ & $\stackrel{2}{(40,787)}$ & $(119,680)$ & $(70,560)$ \\
\hline North-Eastern & . & .. & $\begin{array}{c}1 \\
(185,379)\end{array}$ & - & - & - & $\begin{array}{c}5 \\
(268,486)\end{array}$ & $\stackrel{1}{(25,556)}$ & ${ }^{6}{ }^{6}(453,865)$ & $\begin{array}{c}1 \\
(25,556)\end{array}$ \\
\hline Eustern $\quad$. & $\therefore$ & .. & $\begin{array}{c}1 \\
(182,959)\end{array}$ & - & - & ${ }_{(60,732)}^{2}$ & $(168,401)$ & - & ${ }^{3}(351,360)$ & $(60,732)$ \\
\hline South-Eastern & . & .. & $\begin{array}{c}1 \\
(468,378)\end{array}$ & - & ${ }_{(99,530)}^{2}$ & - & $\begin{array}{c}7 \\
(535,995)\end{array}$ & $\frac{1}{(43,171)}$ & $\begin{array}{c}10 \\
(1,103,903)\end{array}$ & $\stackrel{1}{(43,171)}$ \\
\hline Western $\ldots$ & . & .. & - & $\begin{array}{c}1 \\
(1,054,913)\end{array}$ & $\stackrel{2}{(78,917)}$ & $\begin{array}{c}13 \\
(602,991)\end{array}$ & $(437,295)$ & $\begin{array}{c}7 \\
(775,547)\end{array}$ & $\begin{array}{c}6 \\
(516,212)\end{array}$ & $\stackrel{21}{(2,433,451)}$ \\
\hline Whole of Scotl & & . & $(836,716)$ & $\frac{1}{(1,054,913)}$ & $(178,447)$ & $\begin{array}{c}16 \\
(693,496)\end{array}$ & $\frac{21}{(1,529,857)}$ & $\begin{array}{c}11 \\
(885,061)\end{array}$ & $\stackrel{28}{(2,545,020)}$ & $\frac{28}{(2,633,470)}$ \\
\hline
\end{tabular}




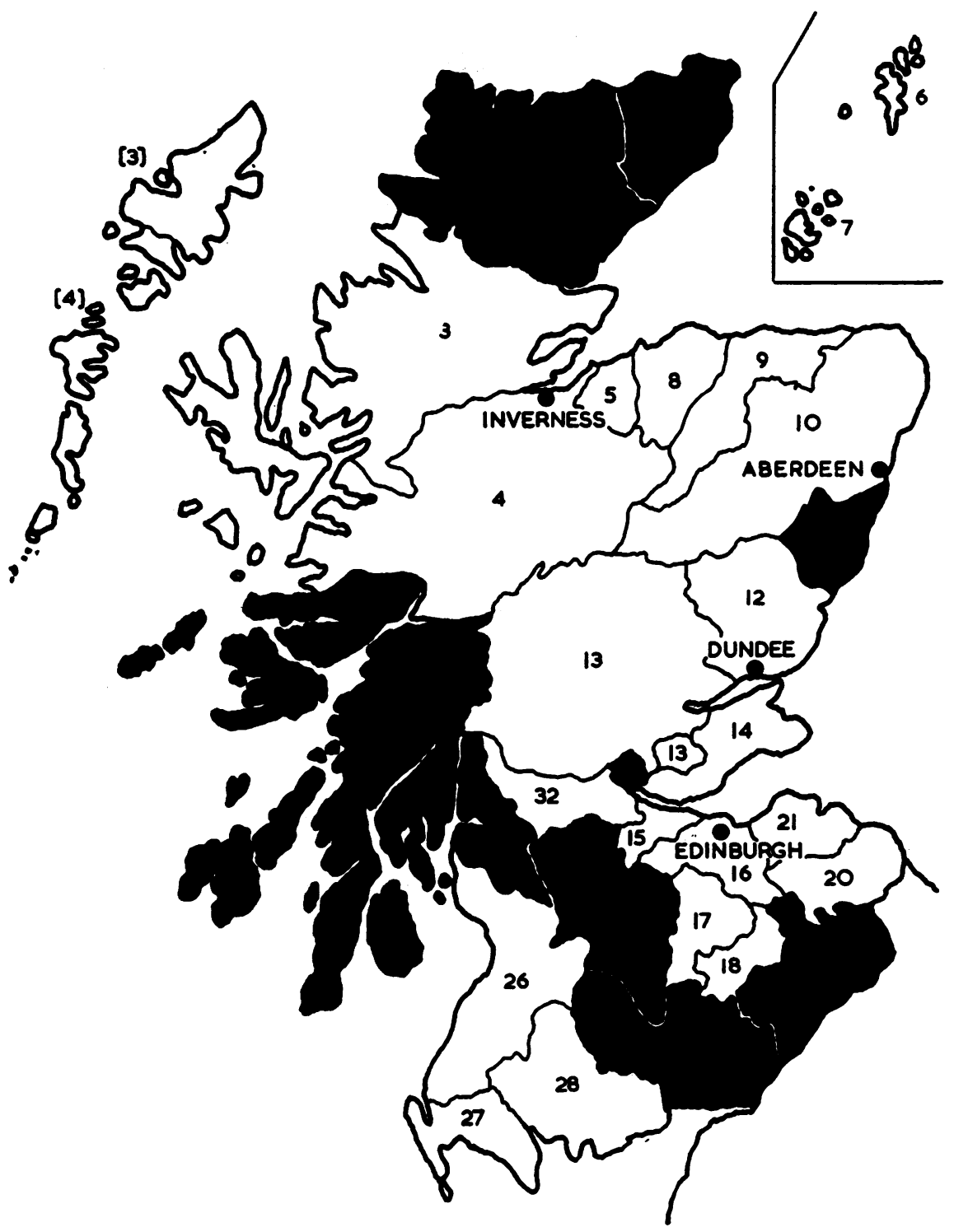

Fig. 4.-Scotland (1959), showing areas (shaded) with over the median death rate from respiratory tuberculosis.

The method has been applied to Scotland, with five hospital regions and local units as described.
One example of the use of the method, in epidemiology, is illustrated in Figs 5 and 6 (overleaf). 


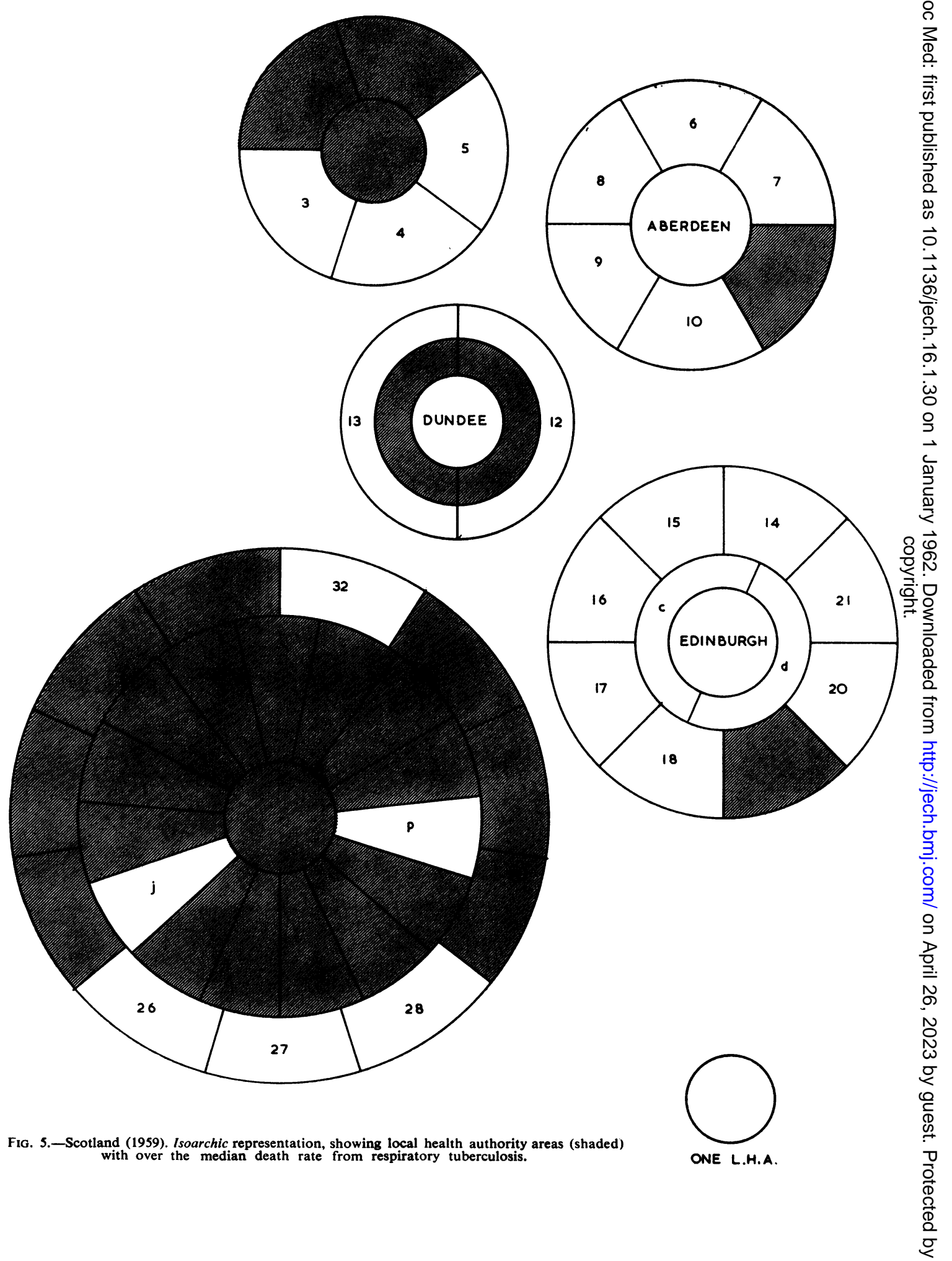




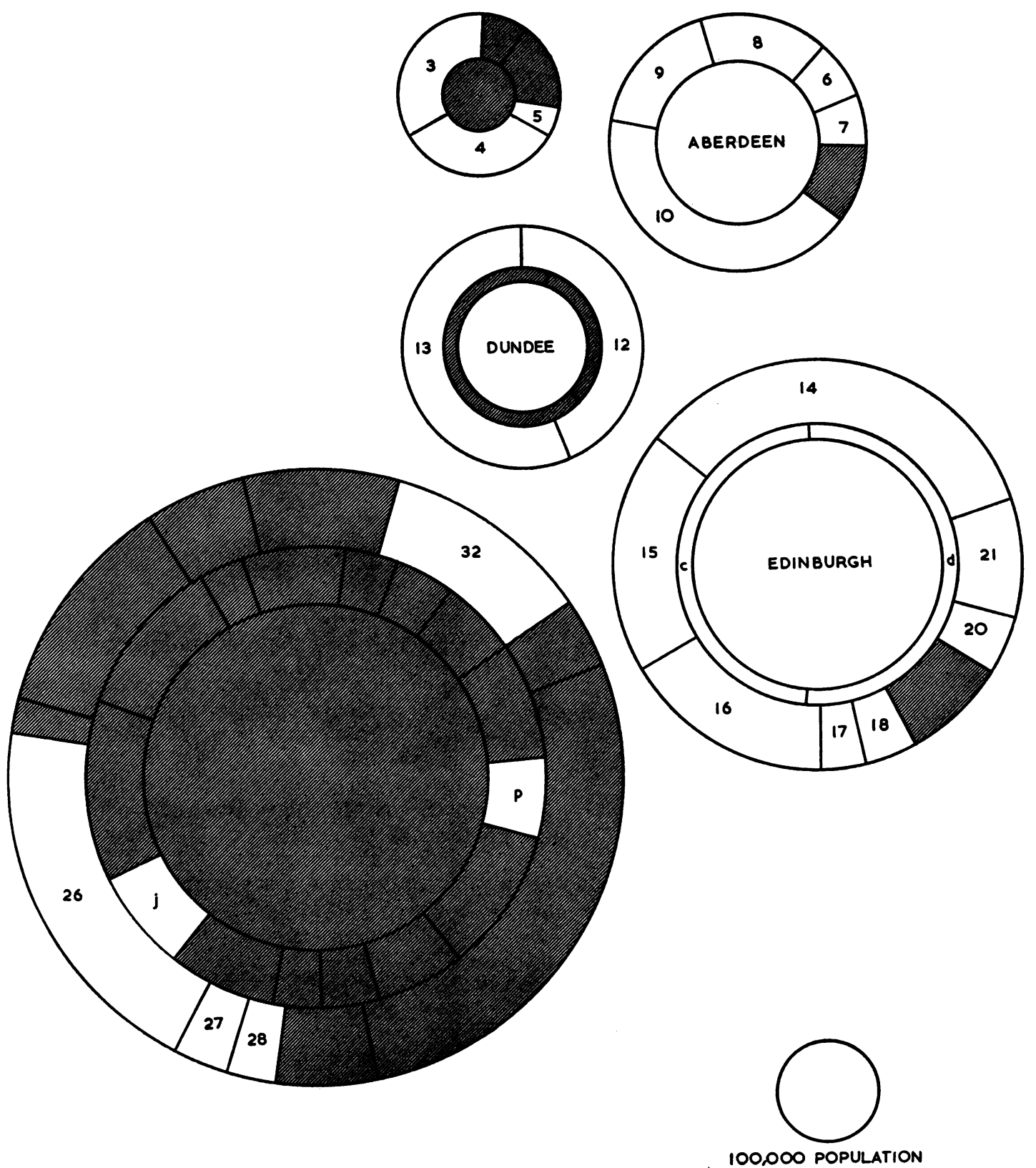

Fig. 6.-Scotland (1959). Isodemic representation, showing local health authority areas and populations (shaded) with over the median death rate from respiratory tuberculosis. 